\title{
The Effects of Carbaryl on the Development of Zebrafish (Danio rerio) Embryos
}

\author{
Elizabeth N. Schock, Windsor C. Ford, ${ }^{2}$ Kirsten J. Midgley, ${ }^{2}$ Joseph G. Fader, ${ }^{2}$ \\ Michael N. Giavasis, ${ }^{2}$ and Michelle L. McWhorter, Ph.D.,
}

\begin{abstract}
In the United States, Sevin ${ }^{\mathrm{TM}}$ brand insecticide is one of the most commonly used insecticides. The active ingredient in Sevin ${ }^{\mathrm{TM}}$, carbaryl (1-napthyl-N-methylcarbamate), is a known acetylcholinesterase (AChE) inhibitor that prevents the breakdown of acetylcholine to acetate and choline at the synapse. While carbaryl successfully causes the death of insects by paralysis, it has also been shown to have negative effects on the development of several nontarget species. To study the effects of carbaryl on nontarget species, zebrafish (Danio rerio) were used, as they are a good model for both toxicology and development studies. Our study suggests that carbaryl induces changes in morphology, specifically in embryo size and shape. Additionally, carbaryl causes defects in heart formation that is characterized by a decrease in heart rate and a developmental delay/defect in cardiac looping. A significant decrease in the number of spinal cord neurons present was also observed. Further investigation showed that there was an increase in cell death in carbaryl-treated embryos. The results indicate that carbaryl may have a greater environmental impact than initially intended. Our study, which was conducted solely by undergraduates at a liberal arts college, indicates that carbaryl may be detrimental to the development of nontarget species.
\end{abstract}

\section{Introduction}

$\mathbf{I}$ NSECTICIDES ARE POWERFUL AGENTS that kill unwanted insects in the applied area. One of the most common insecticides in the United States is Sevin ${ }^{\mathrm{TM}}$. The active ingredient of this particular insecticide, carbaryl (1-napthyl-N-methylcarbamate), was the third highest ranking nonagricultural pesticide and highest ranking nonagricultural insecticide used for 2005 and 2007. ${ }^{1}$ Annually, 4-6 million pounds of carbaryl are distributed in the United States. ${ }^{1}$ Although it effectively kills insects, it has also been observed to have effects on nontarget species, specifically aquatic organisms. ${ }^{2}$ With a half life of 3-8 days, and high levels of carbaryl being used annually, the impact can be significant. ${ }^{3}$ According to the Environmental Protection Agency (EPA), it is probable that carbaryl will leach into groundwater. ${ }^{4}$ The potential impact of carbaryl on nontarget species has not gone unnoticed by several European counties. Germany, Austria, and Sweden have all banned the use of carbaryl. ${ }^{5}$ In order to study the effects of carbaryl on a nontarget aquatic species, zebrafish (Danio rerio) were used as a model.

Carbaryl is a known inhibitor of the enzyme acetylcholinesterase (AChE), which is responsible for converting acetylcholine (ACh), a neurotransmitter, into acetate and choline at the synapse. ${ }^{6}$ Although AChE is expressed in a variety of tissues, it is especially important at the neuromuscular junction. ${ }^{7}$ If the breakdown of ACh does not occur, the neurotransmitter remains bound to the acetylcholine receptor (AChR) and muscle stimulation persists, eventually leading to paralysis due to muscle atrophy. ${ }^{7}$ This can have severe implications on development, especially since AChE is expressed early in somitogenesis at approximately the 6 somite stage in zebrafish. ${ }^{8}$ AChE has been indicated as being important for neuronal development, muscle development, and axon outgrowth. ${ }^{7,9,10}$ If AChE function is completely eliminated, zebrafish experience a severe decrease in motility and premature death. ${ }^{7}$

In addition to being an AChE inhibitor, carbaryl has also been shown to interact with aryl hydrocarbon receptors (AhR). ${ }^{11}$ The roles of AhR are vast and include aiding in cell differentiation, cell proliferation, and regulating metabolic enzymes. ${ }^{12,13}$ AhR are activated by the binding of a ligand in the cytoplasm; this is followed by a translocation of the complex to the nucleus where it recognizes specific DNA sequences. ${ }^{13}$ Transcriptional activation by AhR is facilitated by molecules such as cAMP response element-binding protein (CBP). ${ }^{14}$ When carbaryl is complexed with AhR, CBP is unable to interact with $A h R .{ }^{13}$ This could have several effects downstream in the signaling pathway, specifically in terms of

${ }^{1}$ Biochemistry and Molecular Biology Program, ${ }^{2}$ Department of Biology, Wittenberg University, Springfield, Ohio. 
gene expression. Interestingly, carbaryl can also induce transcriptional activation when it complexes with $\mathrm{AhR} .{ }^{15}$ In terms of interactions of carbaryl with AhR, they can be classified as agonistic (triggering a cellular response) and antagonistic (blocking agonistic responses), implicating that carbaryl can effect gene expression in either a positive or negative manner. ${ }^{13}$ Therefore, carbaryl may affect gene expression directly via $A h R$ or indirectly via CBP.

Zebrafish are a great model for toxicology studies. Embryos can easily be exposed to a potential toxicant by simply introducing the toxicant to water. Because zebrafish embryos are relatively large, molecules can be introduced to their system without the use of injection. ${ }^{16}$ Toxicants, such as carbaryl, simply diffuse across the chorion and into the zebrafish, or if the toxicant does not diffuse thru the chorion, the embryos can be dechorionated. In addition, the effects of the toxicant on the morphology of zebrafish can be easily visualized due to the transparency of the embryos. ${ }^{16}$ Zebrafish were used previously to study the effects of chlorpyrifos $(\mathrm{CPF})$, an organophosphate pesticide that is also an AChE inhibitor, on neurodevelopment. ${ }^{17}$ The success of this study further indicates zebrafish as a good model for toxicology studies. The combination of toxicological relevance with the preexisting knowledge about the development of zebrafish makes them an ideal model for the study of the effects of carbaryl on development.

In previous studies, it was observed that carbaryl retards embryonic development, affects embryo size, and delays hatching. ${ }^{4}$ The data presented here are a complementary analysis that shows that carbaryl not only affects overall morphology, but also heart and neuronal development, and ultimately increases cell death. This indicates that the biological impact of carbaryl may extend beyond its market use as an insecticide.

Wittenberg University is an undergraduate, liberal arts institution with approximately 2000 students located in Ohio. While there is no requirement for independent student research within the Biology and Biochemistry \& Molecular Biology curriculums, faculty within these programs are actively engaged in student research and believe that student research is a tool for teaching science. After being invited to join the laboratory, an incoming undergraduate student discusses the relevant background information and laboratory techniques about his/her specific project with Dr. McWhorter. $\mathrm{He} / \mathrm{She}$ will then usually "shadow" another more senior student in the laboratory to learn specific techniques. Students who join the laboratory and obtain relevant data are then given opportunities to present their research at professional conferences as either poster or oral presentations. In addition, students learn valuable skills that are greatly beneficial as they progress toward graduate or medical school including: 1) critical thinking and problem solving, 2) laboratory skills such as pipette usage and RNA in situ hybridization, 3) critical evaluation of the scientific literature, and 4) oral and written presentation skills.

\section{Materials and Methods}

\section{Fish maintenance}

Adult zebrafish were maintained at $28^{\circ}-30^{\circ} \mathrm{C}$ as previously described. ${ }^{18}$ Embryos were allowed to develop at $28^{\circ} \mathrm{C}$ and staged in hours post fertilization (hpf). ${ }^{19}$ The fish that were used were derived from cross of AB and LF. Wittenberg University's IACUC approval was received for these experiments.

\section{Treatment}

Embryos were exposed to either a $0.2 \%$ methanol control treatment, $20 \mu \mathrm{g} / \mathrm{mL}$ carbaryl, or $40 \mu \mathrm{g} / \mathrm{mL}$ carbaryl (PST-100; Ultra) treatment. The carbaryl stock solution was produced by dissolving carbaryl in 100\% methanol; carbaryl solubility has been previously reported. ${ }^{20}$ Treatment solutions contained a 2:1 ratio of 1-phenyl-2-thiourea $(0.003 \%$ PTU) to embryo medium $^{18}$ and were applied prior to gastrulation. Embryos were kept at $28^{\circ} \mathrm{C}$ and remained in the treatment solution for the duration of the experiments. Methanol or carbaryl treatment was not reapplied.

\section{Survival rates}

Embryos were considered "dead" if they were simply a mass of gray/black cells accompanying the yolk and/or if there was no detectable heart rate by $27 \mathrm{hpf}$.

\section{Whole-mount in situ hybridization}

Whole-mount in situ hybridization was performed using digoxigenin-labeled antisense RNA probes: $c m l c 2^{21}$; gefiltin/ internexin neuronal intermediate filament $\alpha b^{22}$; or gata3. ${ }^{23}$ Whole-mount in situ hybridization protocol (1277073; Roche) was performed as previously described. ${ }^{24}$

\section{Neuronal counting}

For gefiltin 1 studies, neuronal counting began slightly past the hindbrain, at the point where the neurons become parallel, and extended to the tip of the tail. Individual cells were counted conservatively based upon staining. Cells were identified by being a singular unit that was round or oblong in shape. If it was unclear whether one or two cells were present, it was counted as one cell. Distinct separation was necessary for cells to be counted as individual and unique neurons.

\section{Heart beat counting}

The number of heart beats in embryos was counted for one minute in embryos of the same age. Each embryo was counted once. This is easily accomplished because the heart is visible during development. Counting was performed under a Leica S8Ap0 microscope.

\section{Immunohistochemistry}

Immunohistochemistry and imaging were performed essentially as previously described. ${ }^{25,26}$ Znp1 monoclonal antibody was obtained from Hybridoma Bank and was used at $1: 100 ;{ }^{27}$ secondary and tertiary antibodies (mouse PAP system) were obtained from Covance (SMI-5010L and SMI4050L, respectively).

\section{Acridine orange}

Live embryos were dechorionated and placed in $10 \mu \mathrm{g} / \mathrm{mL}$ acridine orange (318337; Sigma) in embryo medium, then incubated for $30 \mathrm{~min}\left(28.5^{\circ} \mathrm{C}\right)$. Embryos were washed three times at $10 \mathrm{~min}$ in embryo medium, then observed under UV light. A Nikon Eclipse E400 microscope with Diagnostic Instruments, Spot camera (V2.2.0) was used to take live images. 


\section{Statistical analysis}

A Student's $t$-test was performed at the $99 \%$ confidence interval for the gefiltin 1 neuron counts and the heart rate data. Kaplan-Meier plots were generated with Minitab ${ }^{\mathrm{TM}}$ software.

\section{Microscopy}

Unless otherwise specified, all images were taken on a Leica S8Ap0 microscope using a Leica DFC290 camera with Leica Image Software V 2.8.1.

\section{Recruitment of students}

Students were either directly selected by Dr. McWhorter or, due to a mutual research interest, inquired themselves about research opportunities available within her laboratory. In Dr. McWhorter's laboratory, it has been extremely helpful to have taken the upper level Developmental Biology course, although not required. In addition, Dr. McWhorter did not accept a student into her laboratory unless she had them in a course previously. With the exception of 1 student who joined the laboratory as a freshmen, all other students were juniors when they joined the laboratory.

\section{Results}

\section{Carbaryl-treated embryos exhibit morphological changes}

In order to assess lethality and gross developmental changes, embryos were exposed to two different concentrations of carbaryl. In previous studies on zebrafish using carbaryl, a concentration of $10 \mu \mathrm{g} / \mathrm{mL}$ was used. ${ }^{28}$ To determine the phenotype at higher concentration of carbaryl, zebrafish were treated with $20 \mu \mathrm{g} / \mathrm{mL}$ and $40 \mu \mathrm{g} / \mathrm{mL}$ carbaryl solutions. Control embryos were exposed to a $0.2 \%$ methanol treatment to match the concentration of methanol in the carbarylcontaining solutions. Methanol treatment of embryos did not result in substantial changes from wild-type morphology or in lifetime expectancy (Figs. 1 and 2). Also, the addition of PTU did not alter the observed morphology of control or carbaryl- treated embryos; melanocyte morphology was similar between methanol control and carbaryl-treated embryos (Data not shown). Embryos were exposed to the treatments prior to gastrulation and remained in the same solution, without reapplying treatment, until they were fixed or analyzed. For embryos $24 \mathrm{hpf}$ to $72 \mathrm{hpf}$, lethality increased with the concentration of the carbaryl in solution (Fig. 1). Concentrations of $40 \mu \mathrm{g} / \mathrm{mL}$ resulted in $100 \%$ lethality between $24-27 \mathrm{hpf}$. Additional survival data were collected to determine when carbaryl-treated embryos were dying prior to $24 \mathrm{hpf}$ (Supplementary Fig. S1; Supplementary Data are available online at www.liebertpub.com/zeb). Embryos appeared to be dying between 10-12 hpf (corresponding with gastrulation) and then again around 22-24 hpf. Those embryos that did survive past gastrulation had severe morphological abnormalities (Supplementary Fig. S2).

In contrast to the $40 \mu \mathrm{g} / \mathrm{mL}$ dose, a concentration of $20 \mu \mathrm{g} /$ $\mathrm{mL}$ allowed $20 \%-30 \%$ of embryos to live for an additional 24-48 hours (Fig. 1), but still showed significant death and morphological changes. All embryos treated with $20 \mu \mathrm{g} / \mathrm{mL}$ carbaryl were dead at $72 \mathrm{hpf}$. Because of the increased study/ observation window, the concentration of $20 \mu \mathrm{g} / \mathrm{mL}$ was used for the duration of the experiment. (Any time the term "carbaryl treated" appears in the remainder of this article, it is referencing a concentration of $20 \mu \mathrm{g} / \mathrm{mL}$ ). These data suggested that the effects of carbaryl are dose-dependent, which are consistent with previous results. ${ }^{28}$

When exposed to carbaryl, zebrafish embryos exhibited a general developmental delay and morphological defects as early as gastrulation (data not shown). Throughout the duration of the study, carbaryl-treated embryos never recover after being exposed to carbaryl, as characterized by an enduring delay in physical development. At $24 \mathrm{hpf}$, the morphological difference was pronounced (Fig. 2). The increased curvature of the tail was especially noticeable (Fig. 2B). As the embryos aged, the physical malformation increased. The embryos were considerably smaller and there were obvious changes in the tail morphology and the cardiovascular development, as evidence by blood pooling around the heart (Fig. 2D). Additionally, when carbaryl-treated embryos were

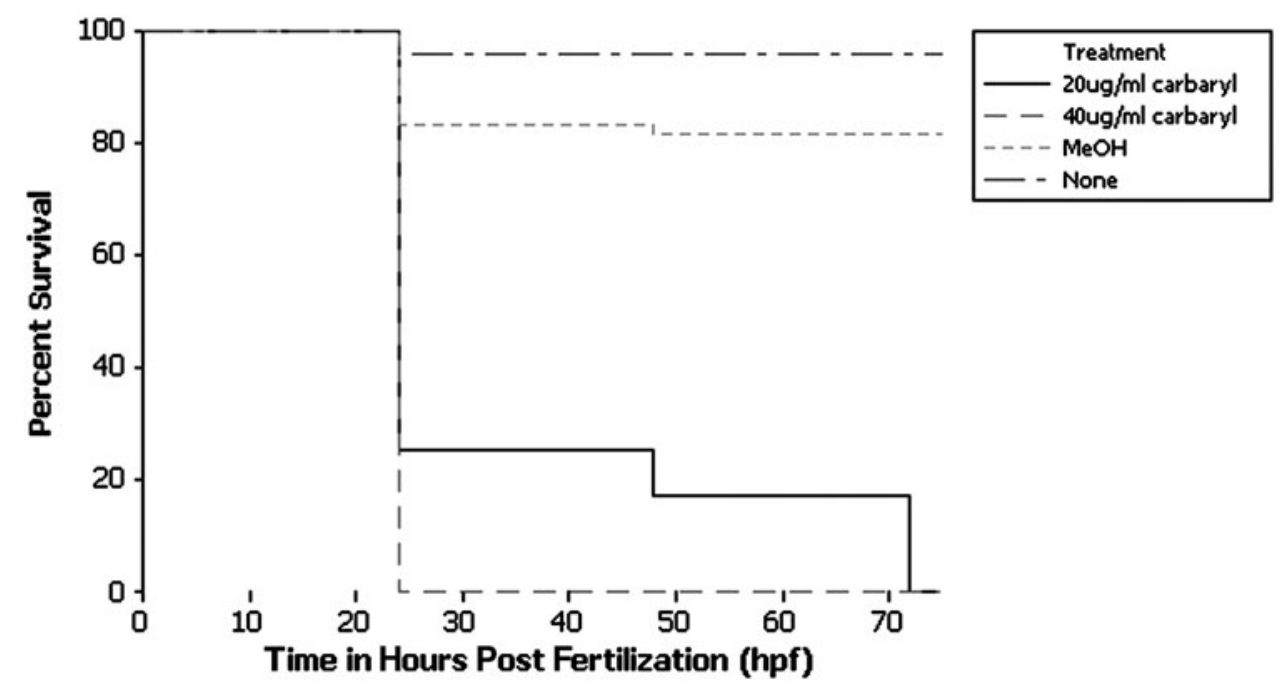

FIG. 1. Exposure to carbaryl results in decreased survival in a dose-dependent manner. Kaplan-Meier survival plots are shown for the different treatment types: none $(n=25), \mathrm{MeOH}(n=61), 20 \mu \mathrm{g} / \mathrm{mL}$ carbaryl $(n=445)$, and $40 \mu \mathrm{g} / \mathrm{mL}$ carbaryl $(n=25)$. 

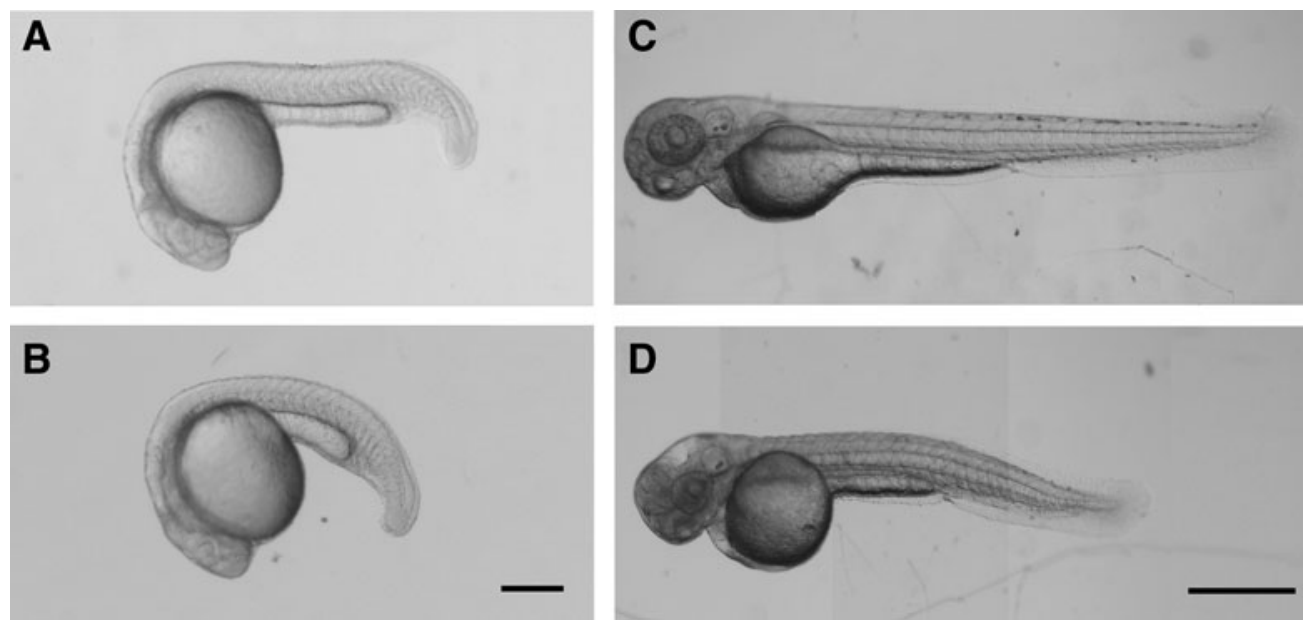

FIG. 2. Carbaryl-treated embryos exhibit morphological defects. Lateral views of $\mathrm{MeOH}$ control embryos (A and C) and $20 \mu \mathrm{g} / \mathrm{mL}$ carbaryl-treated embryos (B and D). Embryos (C and D) have been treated with phenol thiouridine (PTU). (A and B) are $24 \mathrm{hpf}$, and (C and D) are $50 \mathrm{hpf}$. Different focal plane images were merged in Photoshop to produce complied images (C and D). Scale bars: (A and B) $120 \mu \mathrm{m}$; (C and D) $500 \mu \mathrm{m}$.

stimulated with a probe, their response was characterized as having a sluggish escape response by at least $24 \mathrm{hpf}$. After $48 \mathrm{hpf}$, carbaryl-treated embryos often experienced whole body paralysis and were unresponsive to touch. This phenotype is similar to that observed in ache mutant embryos at this age. ${ }^{7}$ Due to these initial observations, cardiac and neurological development were studied further, specifically looking at molecular changes which have previously not been described in other studies.

\section{Carbaryl-treated embryos experience defects in cardiac development}

Because zebrafish are transparent, the development of their heart is easily observed. Upon examination of the carbaryltreated embryos beginning at $24 \mathrm{hpf}$, cardiac edema and blood pooling were observed. Additionally, when the heart rate (beats per minute) was calculated (Fig. 3), there was a statistically significant decrease $(p<0.001)$ in the rate for carbaryltreated embryos compared to controls. This decrease was evident at $24 \mathrm{hpf}$, shortly after the heart begins beating. By $60 \mathrm{hpf}$, the heart rate for carbaryl treated embryos was less than half of the control counterparts. In order to determine if there was a defect that occurred during the development of the heart, early development of cardiac precursors were examined. Cardiac lateral plate mesoderm (LPM) was examined by using a RNA in situ hybridization with a probe assaying for cmlc2, cardiac myosin light chain 2. A decrease in the overall cardiac precursor field was observed as well as defects and delays in cardiac tube migration and fusion (Fig. 4B-D). Additionally, the process of cardiac looping also appeared to be either delayed or defective in a small percentage $(\sim 10 \%)$ of carbaryl-treated embryos (Fig. $4 \mathrm{~F}-\mathrm{H})$. Although a functional heart did form in most cases, it did not perform optimally and had morphological defects.

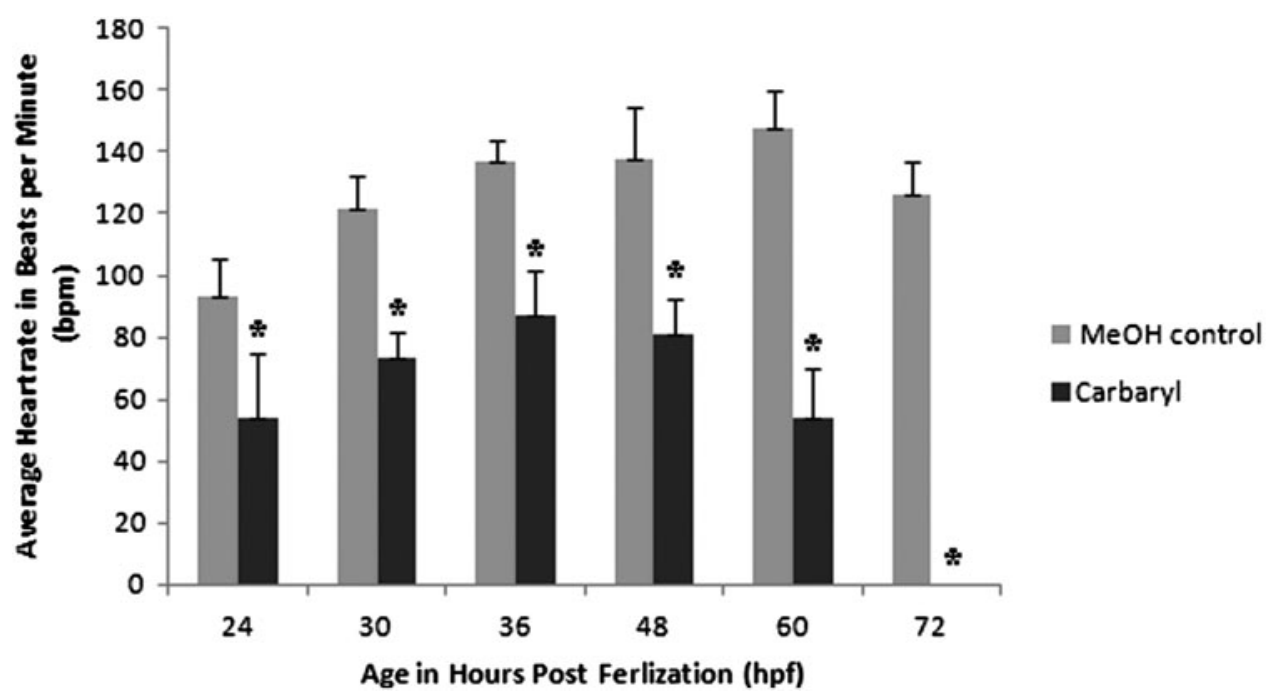

FIG. 3. Carbaryl treatment results in significantly decreased heart rates. Average heart rate (in beats per minute) are shown for $\mathrm{MeOH}$ control $(n=10)$ and carbaryl treatment $(n=69)$. By $72 \mathrm{hpf}$, all carbaryl embryos no longer had beating hearts and were considered deceased. (* indicates $p<0.001$ for Student's $t$-test; error bars indicate standard deviation) 

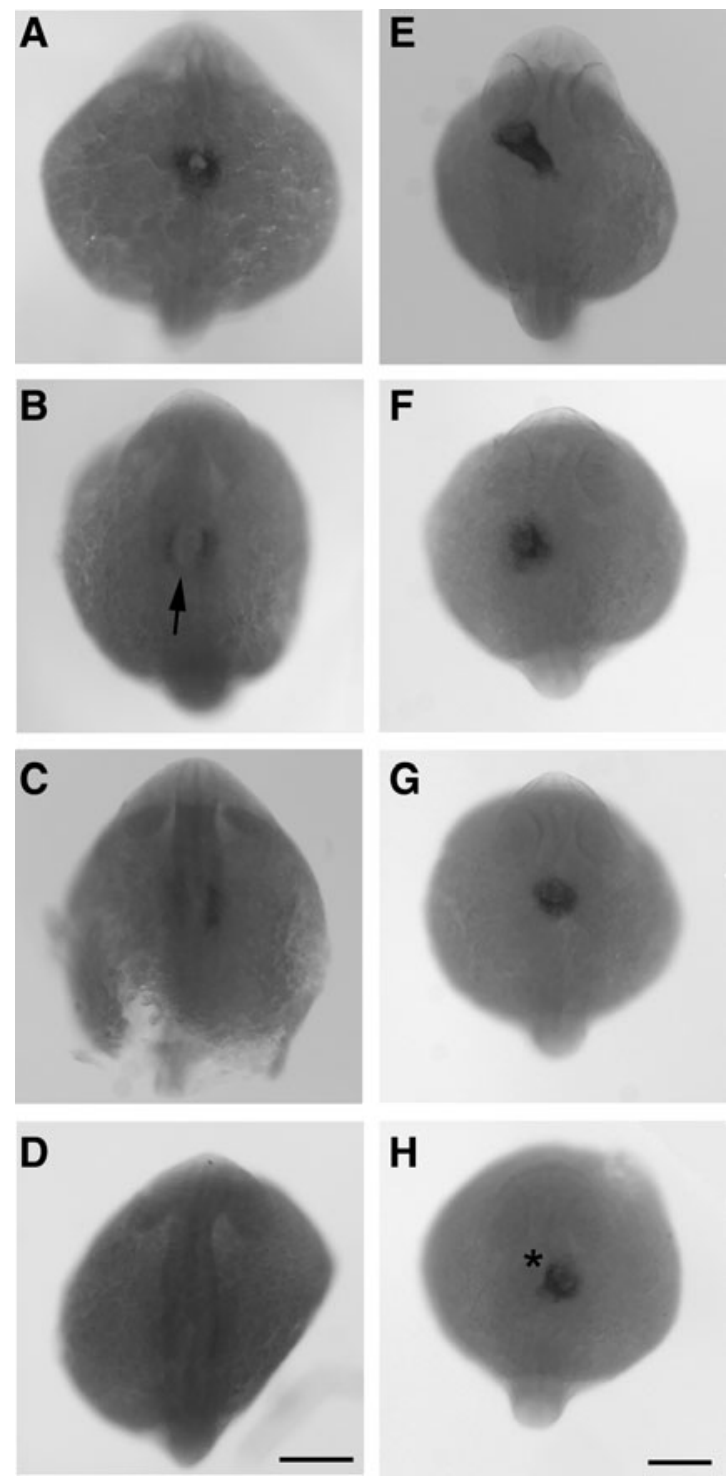

FIG. 4. Carbaryl-treated embryos have both a decrease in overall number of cardiac precursor cells and delay in cardiac precursor migration. Dorsal views of whole-mount RNA in situ hybridization for cardiac myosin light chain 2 $(c m l c 2)$ in $\mathrm{MeOH}$ control (A and E) and carbaryl-treated embryos (B-D, F-H) embryos at $20 \mathrm{hpf}$ (A-D) and $30 \mathrm{hpf}$ (E$\mathrm{H})$. Note the range of phenotypes in carbaryl-treated embryos from reduced endocardial tube fusion (B and $\mathbf{C}$; arrow denotes reduced fusion) to almost complete absence of $\mathrm{cmlc} 2$ expression in cardiac field (D). Also note the range of later phenotypes in which $\sim 10 \%$ of embryos have an endocardial tube that either has substantial delays in looping or fails to loop ( $\mathbf{F}$ and $\mathbf{G})$, or loops to the right side (* denotes looping to the right), instead of to the left $(\mathbf{H})$. Scale bars: (A-D) $50 \mu \mathrm{m}$; (E-H) $75 \mu \mathrm{m}$.

\section{Carbaryl-treated embryos have a reduced number of neurons in the spinal cord and defects in motor axon pathfinding}

By 72 hpf, carbaryl-treated embryos had lost their ability to move and respond to external stimuli, which is consistent with carbaryl's role as an AChE inhibitor and suggested a neuromuscular defect. To determine how neurons were affected by carbaryl, the number of spinal cord neurons was examined. RNA in situ hybridization with a probe directed against the neuronal specific gefilitin1 (internexin neuronal intermediate filament $\alpha b$ ) gene revealed a significant decrease in the number of neurons present from below the hindbrain to the tip of the tail (Fig. 5A-G). This difference was found to be statistically significant $(p<0.001)$. Upon closer examination of the spinal cord, a regional decrease in the number of neurons among carbaryl treated embryos becomes more apparent (Fig. 5 $\mathrm{A}^{\prime}-\mathrm{F}^{\prime}$ ). In addition to the spinal cord defects observed, there was a decrease in gefiltin 1-positive neurons in the brain regions, although those were not quantified (Supplementary Fig. S3).

Upon examination of motor axon development, it was evident that carbaryl embryos exhibited motor axon pathfinding defects. Antibody staining with znp1 revealed errors in motor axon pathfinding compared to controls. The motor axons were truncated, or exhibited uncharacteristic branching patterns (Fig. 6A-D). Motor axon pathfinding was only slightly aberrant in ache mutant embryos. ${ }^{7}$

\section{Carbaryl-treated embryos do not experience changes in relative quantities of non-neuronal ectoderm}

Due to the decrease in the number of neurons, it was hypothesized that either neuronal cells were not specifying properly or that these cells were undergoing cell death. To investigate the first hypothesis, RNA in situ hybridization with a probe directed against the non-neuronal ectoderm specific gata3 gene was performed. In general, there was no global change in the amount of non-neuronal ectoderm in cells, although a slight delay in development was observed, as evident by the presence of a larger yolk plug in carbaryltreated embryos compared to their control counterparts (Fig. 7). Therefore, if neuronal cells were not fated properly, they were not alternatively specified into non-neuronal cells.

\section{Carbaryl-treated embryos have an increase in cell death}

To investigate the hypothesis that the neuronal deficit can be accounted for by an increase in cell death, acridine orange was used to visualize dying cells in live embryos (Fig. 8). Although control embryos did have some dying cells, this is a common characteristic of development. ${ }^{29}$ In contrast, the amount of cell death that carbaryl-treated embryos experienced exceeded that of controls (Fig. 8). In addition, there was a localization of dying cells that appeared to be adjacent to the heart cavity (Fig. 8B, arrow) Also, dying cells along the extent of the brain and spinal cord were detected. The cell death that was observed is consistent with cardiac and neuronal defects described previously.

\section{Discussion}

Using the power of zebrafish as both developmental and toxicological models, our study has shown carbaryl to have a significant impact on early developmental processes. Our results indicate morphological, cardiac, neurological defects, and an increase in cell death when embryos are treated with carbaryl. Further, our results indicate that carbaryl may be having some non-acetylcholinesterase effects. 

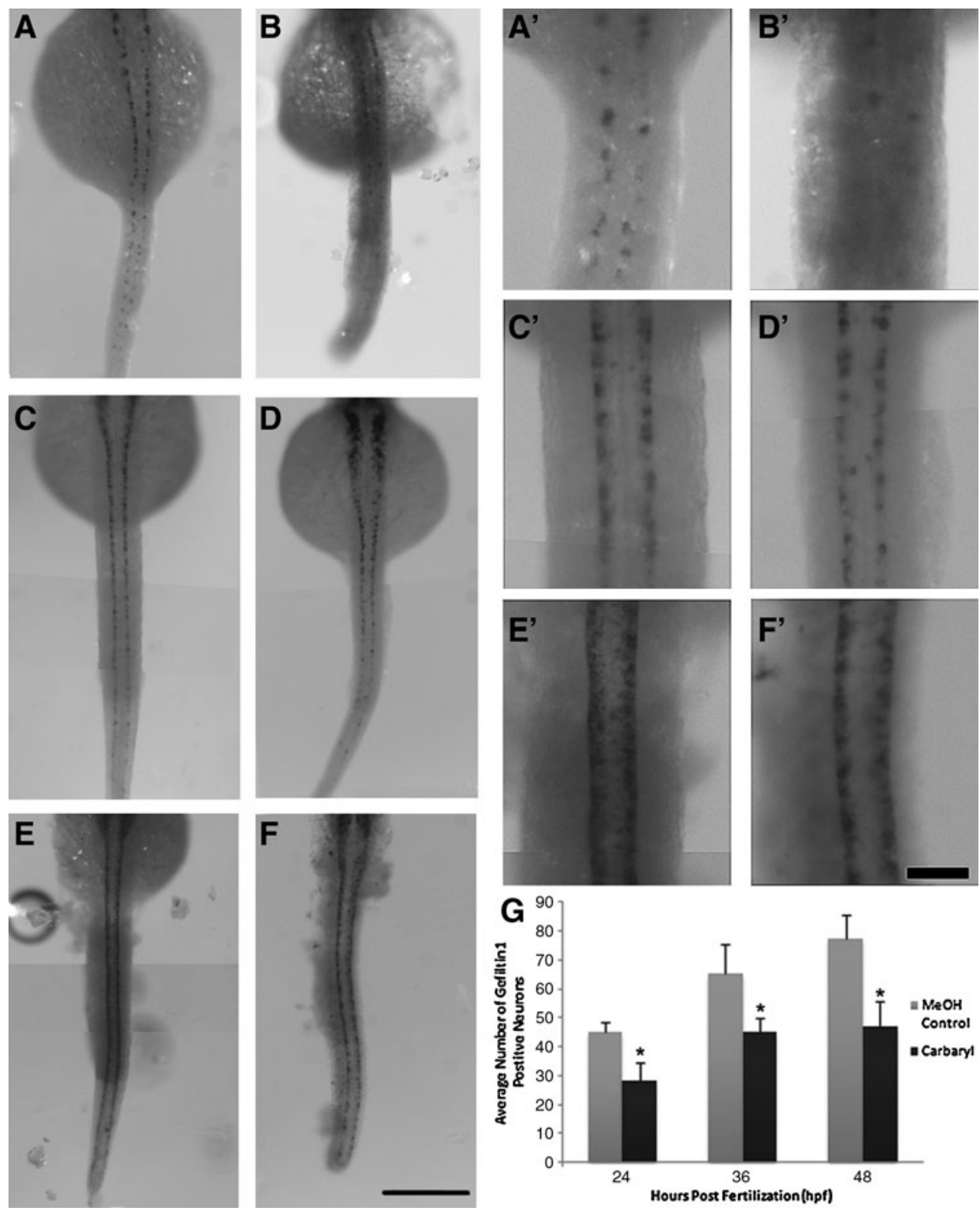

FIG. 5. Carbaryl-treated embryos have a reduced number of gefiltin 1 positive neurons at 24, 36, and $48 \mathrm{hpf}$. Dorsal views of whole-mount RNA in situ hybridization using gefilitin 1 on $\mathrm{MeOH}$ control embryos (A, C, E; $n=89$, 31, 53, respectively) and carbaryl-treated embryos (B, D, F; $n=30,48,31$, respectively) at $24 \mathrm{hpf}$ (A and B), $36 \mathrm{hpf}$ (C and D), and $48 \mathrm{hpf}$ (E and F). Individual neurons are labeled. Enlarged views of panels $\mathbf{A}-\mathbf{F}$ are shown $\left(\mathbf{A}^{\prime}-\mathbf{F}^{\prime}\right)$. Quantification of gefiltin 1 positive cells indicate a statistically significant $(*$ indicates $p<0.001)$ decrease in the number of neurons in carbaryl-treated embryos, where error bars indicate standard deviation (G). Different focal plane images were merged in Photoshop to produce complied images. Also images $\left(\mathbf{A}^{\prime}-\mathbf{F}^{\prime}\right)$ were sharpened in Photoshop. Scale bars: (A-F) $250 \mu \mathrm{m}$; $\left(\mathbf{A}^{\prime}-\mathbf{F}^{\prime}\right) 50 \mu \mathrm{m}$.

\section{Carbaryl exhibits non-acetylcholinesterase effects}

Although carbaryl is characterized as an AChE inhibitor, our results indicate that the role it plays extends far beyond simple inhibition of AChE. Previous studies have examined the effects of loss of functional AChE by studying ache mutant zebrafish embryos. These embryos have impaired motility, decreased response to stimulus, and neuromuscular junction impairments. ${ }^{7}$ Motility impairment in ache embryos begins around $27 \mathrm{hpf}{ }^{7}$ which is similar to when it is observed in carbaryl-treated embryos. Also, total body impairment by 3 days of development was the same for both carbaryl and ache embryos. These observations are consistent with AChE inhibition; however, our data indicates that carbaryl causes a defect as early as gastrulation (Supplementary Fig. 1, and data not shown). ache expression does not occur until the 6 somite stage, well after gastrulation occurs. ${ }^{7}$ Additionally, it was observed in ache mutant embryos that there were no severe defects in motor axon pathfinding of primary motor neurons. ${ }^{7}$ Our data show moderate and severe defects in motor axon pathfinding. Although there are some phenotypic similarities with AChE inhibition, as shown by ache comparison, additional observations indicate that carbaryl may have nonAChE effects on developing embryos. 

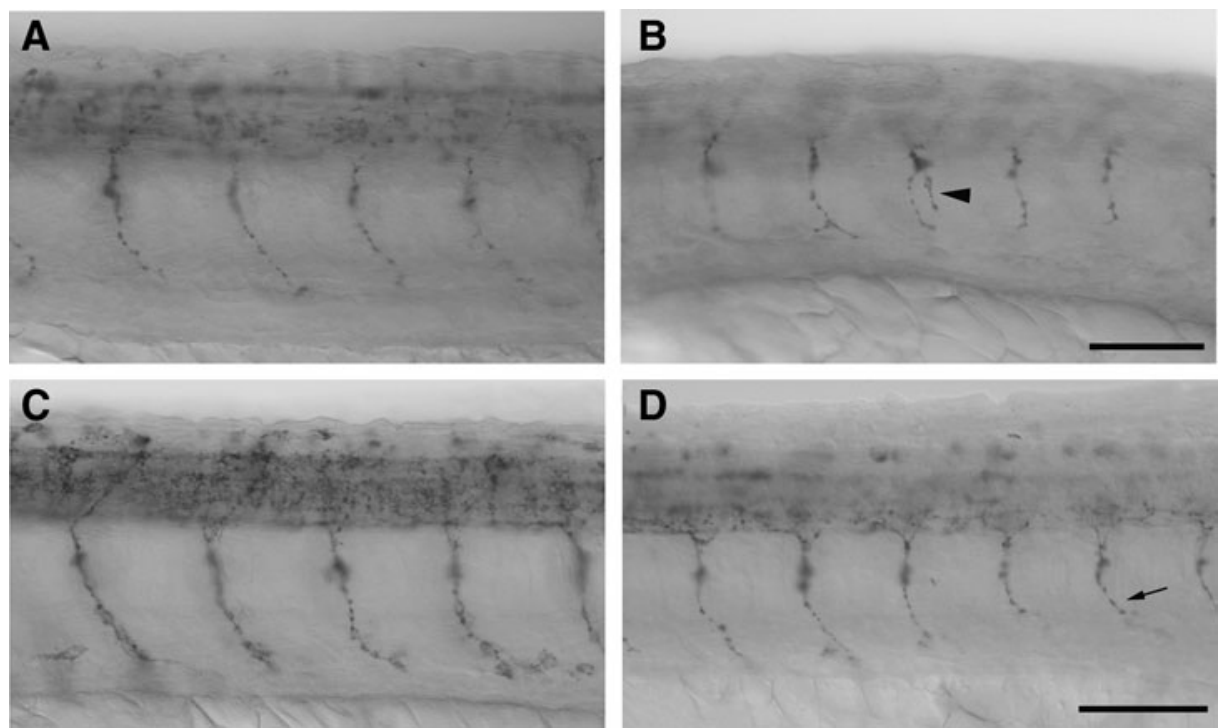

FIG. 6. Carbaryl-treated embryos exhibit errors in motor neuron pathfinding. Lateral views (A-D) of MeOH control (A and C) and carbaryl-treated embryos (B and D) whole-mount antibody-stained for the znp1 antibody showing motor axons at $26 \mathrm{hpf}(\mathbf{A}$ and $\mathbf{B})$ and $32 \mathrm{hpf}(\mathbf{C}$ and $\mathbf{D})$. The arrow indicates points of truncation and the arrowhead indicates excessive branching. Scale bar: (A and B) $25 \mu \mathrm{m}$; (C and D) $30 \mu \mathrm{m}$.


FIG. 7. Carbaryl-treated embryos do not have significant changes in levels of gata 3 expression during gastrulation. Lateral views of gata 3 RNA in situ hybridization on $\mathrm{MeOH}$ control (A, C, E) and carbaryl-treated (B, D, F) embryos at 9 hpf (A and B), 10 hpf (C and D), and 11 hpf (E and F). The ventral side is to the left. Overall, no global change in gata 3 expression is indicated; however, a slight delay in gastrulation is apparent (A and F). Images were brightened using Photoshop. Scale bar: $250 \mu \mathrm{m}$.
In addition, it has been shown that several other AChE inhibitors exhibit non-AChE effects. Zebrafish exposure to tacrine (TAC) or erdophonium (EDRO), known AChE inhibitors, result in changes in cell migration and aberrant neurogenesis. ${ }^{30}$ These effects were not observed in ache embryos, indicating that these compounds are having alternate effects and may be interacting with another target. ${ }^{30}$ It is possible that non-AChE effects of carbaryl are also being observed. Non-AChE effects are also consistent with the previous studies that have found that AhR are affected by carbaryl. ${ }^{11}$ Zygotic AhR expression begins at $4 \mathrm{hpf} .{ }^{31}$ Carbaryl-treated embryos appear to be dying during times in which gastrulation is occurring (Supplementary Fig. S1), it is very possible that carbaryl is interacting with $\mathrm{AhR}$ and altering gene expression via changes in activity of CBP during this time of zygotic gene expression. Assuming these gene expression changes are significant, AhR binding by carbaryl would offer an explanation for the observed non-AChE effects.

\section{A neuronal deficit may result due to an increase in apoptosis}

The results obtained from doing RNA in situ hybridization with a probe assaying for spinal cord neurons, showed that there is a statistically significant decrease in neurons. We proposed two explanations for this observed deficit: failure for proper specification of neuronal-fated cells or an increase in cell death in neuronal-fated cells. If ectoderm cells were not specified properly into neuronal ectoderm, then it would be expected that alternatively, they would be becoming nonneuronal ectoderm. The data obtained examining nonneuronal cells indicated that this is not the case. There was no global change in the amount of non-neuronal ectoderm present between carbaryl treated and control embryos. These data did suggest a slight developmental delay during gastrulation and may indicate a defect in convergence and extension, although this feature has not yet been examined. In 


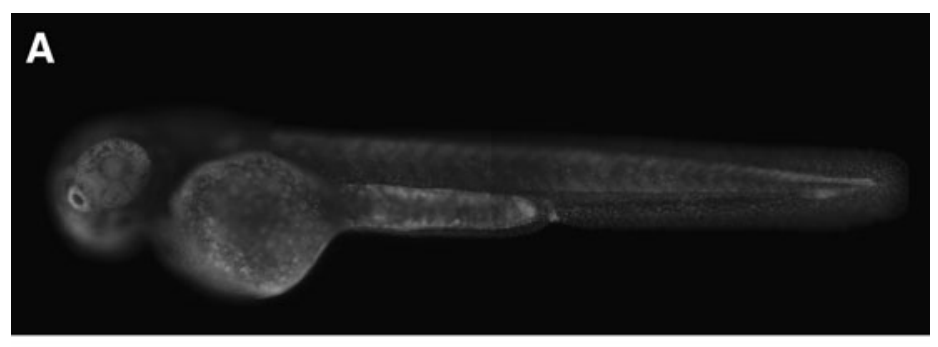

FIG. 8. Carbaryl-treated embryos experience an increase in cell death. Lateral views of $\mathrm{MeOH}$ control (A) and carbaryl-treated (B) embryos exposed to acridine orange at $48 \mathrm{hpf}$. Dying cells near the heart, in the head region, and along the spinal cord are apparent in carbaryl-treated embryos (B; arrows), and far exceed the amount of dying cells observed in $\mathrm{MeOH}$ control embryos. Different focal plane images were merged in Photoshop to produce complied images. Scale bar: $500 \mu \mathrm{m}$.

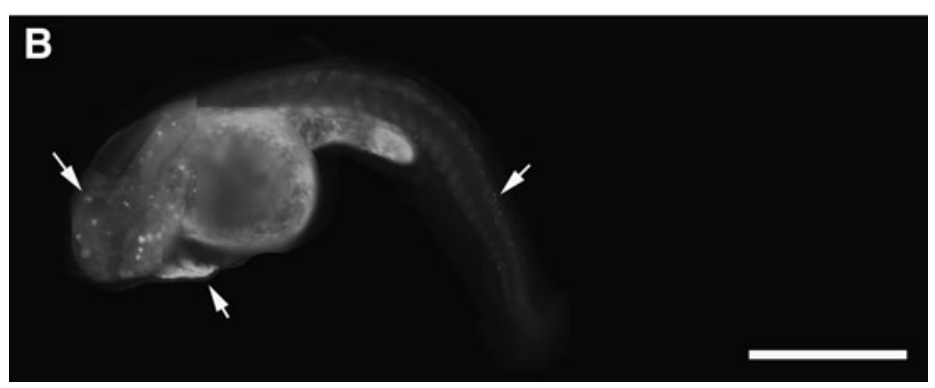

contrast, the assay for cell death indicated that there was an increase in cell death globally. Some of these cells are likely to be neuronal based on their location along the spinal cord of the embryo. In addition, TUNEL assays examining apoptosis suggest that observed cell death may be due to apoptosis, specifically (data not shown). This further implies that the observed decrease in neuronal cells in carbaryl-treated embryos is due to apoptosis, not improper specification. In addition, motor axon pathfinding errors could provide a potential mechanism for neuronal cell apoptosis, as proper contact with the target cell is necessary for the neuron to survive. Although paralysis in carbaryl-treated embryos most likely results from chronic hyperactivation due to AChE inhibition, the observed motor axon defects in carbaryl treated embryos may contribute to paralysis defects in older embryos. It is also possible that a defect in cell proliferation could also explain the decreased number of neurons.

\section{Carbaryl impacts cardiac development and physiology}

A previous study showed that carbaryl affects heart development. ${ }^{28}$ Several of our findings are consistent with their results, including pericardiac edema and decrease in heart rate. ${ }^{28}$ One difference, however, was that a greater difference in heart rate was observed in our study. Additionally, our study observed death at $72 \mathrm{hpf}$, whereas Lin and colleagues continued to count heart rate up until $96 \mathrm{hpf}^{28}$ These important differences can be explained by the use of a two-fold higher concentration of carbaryl treatment for our experiment. This demonstrates that the effects of carbaryl are dosedependent. There were additional differences that were observed between the two experiments that are most likely explainable by concentration differences. In about $10 \%$ of the carbaryl-treated embryos, a defect in cardiac looping was observed. Lin and colleagues did not observe altered looping patterns. ${ }^{28}$ Our study was uniquely different from their study in terms of investigating changes in early cardiac precursors using RNA in situ hybridization. Lin and colleagues did not examine heart development at very early stages, only the ultimate formation of heart chambers and the distance between the sinus venosus and the bulbus arteriosus. The findings presented here suggest there are fewer cardiac precursor cells; in addition, a delay or defect in their migration to the midline occurs, which is a novel observation. This heart defect could offer an explanation for the observed blood pooling.

\section{Carbaryl toxicity has environmental implications}

In terms of environmental implications, we have shown that the carbaryl acts in a dose-dependent manner. Although a concentration of $20 \mu \mathrm{g} / \mathrm{mL}$ would not be found in all water sources, this concentration has been discovered in some surface and ground water. ${ }^{32}$ At this concentration, carbaryl is sufficient to cause damage to the development of aquatic wildlife. It would be interesting to explore how the concentration of carbaryl in water sources varies during different agricultural seasons and after rainfall. Concentrations may be highly variable and equal or exceed our $20 \mu \mathrm{g} / \mathrm{mL}$ concentration of carbaryl, depending on weather conditions. These detailed studies would help to give an indication of how high concentrations are within the environment. Based on our results, the effects of carbaryl would be predicted to have a larger impact on the entire aquatic ecosystem and to affect more species than just the targeted insects.

\section{Strategies for undergraduate research}

This research project was carried out solely by undergraduate students at Wittenberg University. This manuscript was written by the first author of the paper (Elizabeth N. Schock) with editorial comments/suggestions from the corresponding author (Michelle L. McWhorter); however, the research was a compilation of work from the 5 student authors. Wittenberg has some funding for undergraduate student research, including supply grants, summer grants (both for the student and the mentoring faculty member), and travel grants to present research at scientific meetings. Summer grant support was crucial for 2 student authors of this project, as it allowed them to become immersed in laboratory science for an entire summer. In addition to financial support, the process of writing the grant(s) helped facilitate student learning; through writing the 
grant(s), students better understood and contextualized the project. In addition, travel to meetings allowed students to present their research and discuss the research project with others, thus reinforcing the scientific process. Four of the 5 student authors presented their research findings at professional scientific meetings, which were funded by the University.

One key strategy for obtaining publication quality research from undergraduate students was to assign a single, initial experiment with a concrete objective to a student who had recently joined the laboratory. Assigning many pieces of the same puzzle to several students was an efficient method for obtaining data. Some students, after joining the laboratory, found that they were not well suited to laboratory research and quickly abandoned the project. In contrast, the student authors of this study continued to progress and take on additional projects and responsibilities. To increase commitment to research at Wittenberg University, students may take course credit for research within the laboratory, particularly when, as in the Biology and Biochemistry and Molecular Biology curriculums, students apply credit towards their majors. Three of the 5 student authors successfully completed course credit for their independent research. Our undergraduate laboratory also fostered mentoring of underclassmen by the upperclassmen. Not only did this facilitate learning by the underclassmen, but also reinforced the comprehension of the upperclassmen. Our future goal is to give more opportunities for underclassmen (freshmen and sophomores) within the laboratory so that they can, not only be mentored by the upperclassmen, but that these students will have more time to produce publication quality experiments before graduating. This is often a balancing act with the availability of the faculty mentor and the normal "critical mass" within a laboratory, which in our case has been 2-4 students. The implementation of these strategies allowed for undergraduates to obtain publication quality data and to publish their research in a peer-reviewed scientific journal.

\section{Acknowledgments}

We would like to thank Min An and Paul Henion (The Ohio State University, Columbus, $\mathrm{OH}$ ) for DNA constructs for RNA probe production and Jamie Jontes (The Ohio State University, Columbus, OH) for gefiltin RNA probes; Joshua Waxman (Cincinnati Children's Hospital Medical Center, Cincinnati, $\mathrm{OH}$ ) for acridine orange (reagents and protocol); Doug Andrews (Wittenberg University, Springfield, $\mathrm{OH}$ ) for assistance with the Kaplan-Meier survival curve; and Wittenberg University for Student Development Summer Grants (for Elizabeth N. Schock and Kirsten J. Midgley). The znp1 monoclonal antibody developed by B. Trevarrow was obtained from the Developmental Studies Hybridoma Bank developed under the auspices of the NICHD and maintained by The University of Iowa, Department of Biology, Iowa City, IA 52242.

\section{Author Contributions}

Elizabeth N. Schock graduated from Wittenberg University in 2012 with a Bachelor's of Science in Biochemistry and Molecular Biology. Her contributions to the project include being the primary author of this manuscript and obtaining the gefiltin 1, gata3, and acridine orange data.
Windsor C. Ford attends Wittenberg University where he is working to complete his Bachelor's of Arts in Economics with minors in Biology, Chemistry, and Computational Science (2014). He has also studied abroad at the University of Oxford. His contributions to the project include obtaining mortality, morphology, and cardiac data.

Kirsten J. Midgley graduated from Wittenberg University in 2011 with a Bachelor's of Science in Biology. Kirsten now attends Georgetown University School of Medicine. Her primary contributions to the project were obtaining mortality data and preliminary gefiltin 1 data.

Joseph G. Fader graduated from Wittenberg University in 2011 with a Bachelor's of Science in Biology. His primary contribution to the project was preliminary gefiltin 1 data.

Michael N. Giavasis graduated from Wittenberg University in 2012 with a Bachelor's of Science in Biology. His primary contribution to the project was the collection of survival data including dose-dependent data.

Michelle L. McWhorter is an Assistant Professor of Biology at Wittenberg University. All experiments for the project were carried out in her research laboratory. As the research mentor, she recruited research students, instructed students on the background and experimental techniques necessary for the project, oversaw all aspects of the project, wrote the education sections of the manuscript, and provided editorial comments and changes to the remainder of the manuscript.

\section{Disclosure Statement}

No competing financial interests exist.

\section{References}

1. Grube AD, Kiely $\mathrm{T}, \mathrm{Wu}$ L. Pesticides Industry Sales and Usage: 2006 and 2007 Market Estimates. United States Environmental Protection Agency 2011;41.

2. Hertel RF. Methyl Parathion Environmental Heath CriteriaEHC 145. World Health Organization (WHO), 1993.

3. Liu D, Thomson K, Strachan WMJ. Biodegradation of carbaryl in simulated aquatic environment. Bull Environ Contam Toxicol 1981;27:412-417.

4. Todd NE, Van Leeuwen M. Effects of Sevin (carbaryl insecticide) on early life stages of zebrafish (Danio rerio). Ecotoxicol Environ Safety 2002;53:267-272.

5. Koul O, Cuperus GW. Ecologically Based Integrated Pest Management. CABI Publishing, Cambridge, MA, 2007.

6. Cox C. The problems with Sevin (carbaryl). J Pesticide Reform 1993;13:31-36.

7. Behra M, Cousin X, Bertrand C, Vonesch JL, Biellmann D, Chatonnet A, Strahle U. Acetylcholinesterase is required for neuronal and muscular development in the zebrafish embryo. Nature Neurosci 2002;5:111-118.

8. Bertrand C, Chatonnet A, Takke C, Yan YL, Postlethwait J, Toutant JP, Cousin X. Zebrafish acetylcholinesterase is encoded by a single gene localized on linkage group 7. Gene structure and polymorphism: Molecular forms and expression pattern during development. J Biol Chem 2001;276:464-474.

9. Hanneman EH. Diisopropylfluorophosphate inhibits acetylcholinesterase activity and disrupts somitogenesis in the zebrafish. J Exp Zool 1992;263:41-53.

10. Hanneman E, Westerfield M. Early expression of acetylcholinesterase activity in functionally distinct neurons of the zebrafish. J Comp Neurol 1989;284:350-361. 
11. Mandal PK. Dioxin: A review of its environmental effects and its aryl hydrocarbon receptor biology. J Comp Physiol B-Biochem Syst Environ Physiol 2005;175:221-230.

12. Andrieux L, Langouet S, Fautrel A, Ezan F, Krauser JA, Savouret JF, Guengerich FP, Baffet G, Guillouzo A. Aryl hydrocarbon receptor activation and cytochrome P450 $1 \mathrm{~A}$ induction by the mitogen-activated protein kinase inhibitor U0126 in hepatocytes. Mol Pharmacol 2004;65: 934-943.

13. Boronat S, Casado S, Navas JM, Pina B. Modulation of aryl hydrocarbon receptor transactivation by carbaryl, a nonconventional ligand. FEBS J 2007;274:3327-3339.

14. Hankinson O. Role of coactivators in transcriptional activation by the aryl hydrocarbon receptor. Arch Biochem Biophys 2005;433:379-386.

15. Casado S, Alonso M, Herradon B, Tarazona JV, Navas JM. Activation of the aryl hydrocarbon receptor by carbaryl: Computational evidence of the ability of carbaryl to assume a planar conformation. Environ Toxicol Chem 2006;25:3141-3147.

16. Linney E, Upchurch L, Donerly S. Zebrafish as a neurotoxicological model. Neurotoxicol Teratol 2004;26:709-718.

17. Levin ED, Swain HA, Donerly S, Linney E. Developmental chlorpyrifos effects on hatchling zebrafish swimming behavior. Neurotoxicol Teratol 2004;26:719-723.

18. Westerfield M. The Zebrafish Book. University of Oregon Press. Eugene, 1995.

19. Kimmel CB, Ballard WW, Kimmel SR, Ullmann B, Schilling TF. Stages of embryonic development of the zebrafish. Dev Dyn 1995;203:253-310.

20. Carpenter CP, Weil CS, Palm PE, Woodside MW, Nair JH, III, Smyth HF, Jr. Mammalian toxicity of 1-naphthyl-Nmethylcarbamate (Sevin insecticide). Agricult Food Chem 1961;9:30-39.

21. Yelon D, Ticho B, Halpern M, Stainier DYR. Cardiac anterior-posterior patterning and the essential early role of dhand in the zebrafish. Develop Biol 1999;210:211-211.

22. Leake D, Asch WS., Canger AK, Schechter N. Gefiltin in zebrafish embryos: Sequential gene expression of two neurofilament proteins in retinal ganglion cells. Differentiation 1999;65:181-189.

23. Neave B, Rodaway A, Wilson SW, Patient R, Holder N. Expression of zebrafish Gata-3 (Gta3) during gastrulation and neurulation suggests a role in the specification of cell fate. Mech Devel 1995;51:169-182.

24. Thisse C, Thisse B, Schilling TF, Postlethwait JH. Structure of the zebrafish snail1 gene and its expression in wild-type, spadetail and no tail mutant embryos. Development 1993;119:1203-1215.

25. Beattie CE, Melancon E, Eisen JS. Mutations in the stumpy gene reveal intermediate targets for zebrafish motor axons. Development 2000;127:2653-2662.

26. McWhorter ML, Monani UR, Burghes AHM, Beattie CE. Knockdown of the survival motor neuron $(\mathrm{Smn})$ protein in zebrafish causes defects in motor axon outgrowth and pathfinding. J Cell Biol 2003;162:919-931.

27. Melancon E, Liu DW, Westerfield M, Eisen JS. Pathfinding by identified zebrafish motoneurons in the absence of muscle pioneers. J Neurosci 1997;17:7796-7804.

28. Lin CC, Hui MNY, Cheng SH. Toxicity and cardiac effects of carbaryl in early developing zebrafish (Danio rerio) embryos. Toxicol Appl Pharmacol 2007;222:159-168.

29. Cole LK, Ross LS. Apoptosis in the developing zebrafish embryo. Devel Biol 2001;240:123-142.

30. Behra M, Etard C, Cousin X, Strahle U. The use of zebrafish mutants to identify secondary target effects of acetylcholine esterase inhibitors. Toxicol Sci 2004;77:325-333.

31. Mattingly CJ, McLachlan, JA, Toscano WA. Green fluorescent protein (GFP) as a marker of aryl hydrocarbon receptor (AhR) function in developing zebrafish (Danio rerio). Environ Health Persp 2001;109:845-849.

32. Jones RD, Steeger T. Revised EFED Risk Assessment of Carbaryl in Support of the Reregistration Eligibility Decision (RED). United States Environmental Protection Agency 2003;178.

Address correspondence to: Michelle L. McWhorter, Ph.D. Department of Biology Wittenberg University P.O. Box 720

Ward Street at North Wittenberg Avenue Springfield, OH 45501

E-mail: mmcwhorter@wittenberg.edu 